GU J Sci, Part C, 6(3): 605-620 (2018)

Gazi Üniversitesi
Fen Bilimleri Dergisi
PART C: TASARIM VE TEKNOLOJI
dergipark.gov.tr/http-gujsc-gazi-edu-tr

\title{
Yüzey Yerleștirmeli Kalıcı Mıknatıslı Senkron Generatörlerin Tutma Torkunun Azaltılması İçin Stator Yapılandırması
}

\author{
Durmuş UYGUN ${ }^{1,}$ Yücel ÇETINCEVIZ ${ }^{2 *}$ \\ ${ }^{1}$ Ege Dinamik Elektromekanik Enerji ve Robot Sistemleri A.Ş, Teknokent (DEPARK), Buca/ IZMIR \\ ${ }^{2}$ Kastamonu Üniversitesi, Mühendislik Mimarlık Fakültesi, Elektrik Elektronik Mühendisliği Bölümü, 37150, Merkez/KASTAMONU
}

\begin{abstract}
$\ddot{O} z$
Makale Bilgisi

Başvuru: 07/02/2018

Düzeltme: $17 / 05 / 2018$

Kabul: 29/05/2018

Anahtar Kelimeler

Kalıcı miknatıslı senkron

Bu çalışmada, yüzey yerleștirmeli kalıcı mıknatıslı senkron generatörde meydana gelen tutma torkunu azaltmak için stator nüvesinde gerçekleştirilen yapısal değişiklikler sunulmaktadır. Bu yapısal değişikliklerin tutma torku ve generatör performansı üzerine etkisi araştırılmış, 2B-3B sonlu elemanlar analiz (SEA) ve analitik sonuçları karşılaştırmalı olarak verilmiştir. Tutma torkunun hesaplanması için gerekli olan hava aralığı akı yoğunluğunun elde edilmesinde manyetik eşdeğer devre ve bağıl geçirgenlik modeli kullanılmıştır. Hava aralığı ve mıknatıs bölgelerindeki manyetik alan öncelikle oluk etkisiz olarak hesaplanmış, daha sonra uygun bir şekilde olukların dâhil edilmesiyle elde edilen bir bağıl geçirgenlik fonksiyonu (düzeltme faktörü) dikkate alınarak tekrar ifade edilmiştir. Önerilen yapısal değişikliği ve analitik yöntemi uygulamak için, 4-kW, 24-kutuplu ve 72 oluklu radyal akılı makine tasarlanmış ve optimize edilmiştir.
\end{abstract} generatör

Tutma torku

Bağll geçirgenlik

Keywords

Permanent magnet synchronous generator Cogging torque

Relative permeance

\section{Stator Configuration for Cogging Torque Minimization of Surface Mounted Permanent Magnet Synchronous Generators}

\begin{abstract}
In this study, we present the structural changes in the stator core to reduce the cogging torque in a surface-mounted permanent magnet synchronous generators. The effect of these structural changes on cogging torque and generator performance has been investigated, 2D-3D finite element analysis (FEA) and analytical results have been given comparatively. The magnetic equivalent circuit and the relative permeability models have been used to obtain the airgap flux density required for the calculation of cogging torque. Airgap and magnetic field in the magnet area have been firstly calculated as slotless effect and then re-expressed taking into account a relative permeability function (correction factor) obtained by appropriately adding slots. A 4$\mathrm{kW}, 24$-pole, 72-slot radial-flux machine has been designed and optimized to implement the proposed structural change and analytical method.
\end{abstract}

\section{GİRIŞ (INTRODUCTION)}

Tutma torku, Kalıcı Mıknatıslı (KM) generatörün rotoru, statoru yüksüz durumda iken döndürüldüğünde mili tarafindan üretilen torkdur. Tutma torku KM'lı makinaların geometrilerinin neden olduğu doğal bir özelliğidir [1]. KM'lı generatörlerde tutma torkunu azaltmak önemli bir husustur çünkü generatörün kendi başlangıç yeteneğini etkiler ve rüzgâr türbinlerinde gürültü ve mekanik titreşim üretir $[2,3]$. Ayrıca torkdaki dalgalanmaların da ana bileşenidir [1].

Tutma torkunun azaltılması ile ilgili olarak literatürde birçok yöntem önerilmiştir. Kutup başına kesirli oluk sayısı, stator yığınında veya mıknatıs kutuplarında çarpıklık işlemi [4-6], kutup yayı/kutup adımı oranı değişimi (0-1), eksenel bölütleme veya mıknatıs kaydırma bu yöntemlerden bazılarıdır [ 1-3, 7,8]. Ayrıca oluk açıklığı, mıknatıs kalınlığı ve hava aralığı genişliği gibi parametrelerin diğer çıkış değerleri de göz önünde bulundurularak optimum değerlerinin bulunması, tutma torkunu azaltmak için diğer bir yaklaşımdır [8]. 
Stator yığınında çarpıklık işlemi her ne kadar çok tercih edilse de nihai ürünün imalatını karmaşıklaştırmasından dolayı ilave maliyetlere neden olmaktadır. $\mathrm{Bu}$ yöntem sargı yerleşimini zorlaştırabilir, etkin oluk alanını azaltır, iletken uzunluğu artar ve dolayısıyla stator direnci de artar [3].

Hava aralığı manyetik alan yoğunluğu, makine performansının değerlendirilmesinde değerli bilgiler sağlar. Manyetik alan yoğunluğunun bilgisi sadece makine performansının hesaplanmasına imkân sağlamaz, aynı zamanda tutma torku, torkdaki dalgalanmalar, zıt emk dalga şekli gibi etkilerin hesaplanmasina da imkan verir [9].

Hava aralığı alan yoğunluğunu değerlendirmek için bazı analitik çözüm modelleri geliştirilmiștir. Alt alan modeli [10,11-17], bağ1l geçirgenlik modeli [11,18-21] ve konformal dönüşüm modeli [22-26] hava aralığı manyetik alan hesabında genellikle kullanılan yöntemlerdir. Bu analitik yöntemlerin hepsinde hava aralığındaki manyetik alan, KM'ın alan uyartım kuvvetini temsil eden birinci fonksiyonun bir ürünü olarak hesaplanır [12]. Kaynak [13]'de KM makinelere uygulanan analitik modeller üzerine kapsamlı inceleme gerçekleştirilmiştir. KM makinalarda manyetik alanı tahmin etmek için oluk etkilerini ve stator dişini dikkate alan veya almayan çeşitli metotlar geliştirilmiştir [10]. Zhu vd. (1993), hava aralığı akı yoğunluğunu oluk etkili 2D bağıl geçirgenlik fonksiyonunu kullanarak ifade etmiştir. Oluk etkili hava aralığı ak1 yoğunluğunu, oluksuz hava aralığ1 akı yoğunluğunu bağıl geçirgenlik fonksiyonu ile çarparak elde etmiştir [22]. Zarko vd. (2006), kaynak [22]'den farklı olarak, her bir noktanın konformal dönüşüm ile tahmin edildiği karmaşık bağıl geçirgenlik fonksiyonunu önermektedir. Burada tüm karmaşık bağıl geçirgenlik dalga şekli hesaplandığından, oluk etkisini açıklamak için elde edilen hava aralığı akı yoğunluğu kaynak [22]'ün bağıl manyetik geçirgenlik fonksiyonu ile karşılaştırıldığında, SEA sonuçları ile daha iyi bir eşleşme gösterir [24]. Diğer bir yöntem olan alt alan modeli de, önceden tanımlanmış sınır ve arayüz koşulları ile değişkenlerine ayırma tekniği kullanılarak tüm alt bölgelerde (hava aralığı bölgesi, KM bölgesi, oluk ve oluk açıklı̆ğ bölgesi) Poisson veya Laplas denklemlerinin direk çözümüne dayanır [10].

$\mathrm{Bu}$ çalışmada hava aralığı akı yoğunluğu, zıt emk ve tutma torku ifadelerinin elde edilmesi için bağıl geçirgenlik modelini kullanan bir çalışma sunulmuştur. Önerilen bu analitik yöntemde öncelikle manyetik alan oluk etkisiz olarak hesaplanmış ve daha sonra 2-boyutlu makine modeli (açısal konum ve radyal konuma bağlı olarak) üzerinde elde edilen fonksiyon kullanılarak tekrar ifade edilmiştir. Diğerlerinden farklı olarak, tutma torkunun azaltılmasına yönelik önerilen stator modeli için analizler gerçekleştirilmiştir. Ayrıca, tutma torkunu azaltmak için yukarıda bahsedilen yöntemlerin dışında statorda yardımcı dişler [27] açılarak geliştirilen yeni stator yapısının tutma torkuna ve indüklenen gerilime etkisi ortaya konmuştur. Yeni yapının analitik çözümü için bağıl geçirgenlik fonksiyonu kullanılmıştır. Ayrıca analitik çözüm sonuçları SEA ile karşılaştırılarak doğruluğu gösterilmiştir.

\section{HAVA ARALIĞI MANYETIK ALAN DAĞILIMI (AIRGAP MAGNETIC FIELD DISTRIBUTION)}

Hava aralığı ve mıknatıs bölgelerindeki manyetik alana ilişkin, manyetik devre modeli kullanılarak yapılan açıklamalar, hava aralığındaki stator yüzeyinin sonsuz olarak geçirgen olduğu oluksuz bir durum için geçerlidir [28-32]. Bu çalışmadaki oluklu çözüm modelinde ise, manyetik alan oluk yerleşiminin yanı sıra mıknatıs özellikleri ve geometrik boyutların bir fonksiyonudur.

Generatöre ait genel özellikler Tablo 1'de verilmiştir. Şekil 1 ise oluk ve mıknatısların yerleşimini sunan generatör kesitini göstermektedir. Makinenin kalıcı mıknatıs alan yoğunluğu stator oluğundan etkilenir. Oluk etkisiz hesaplanan manyetik alan dağılımı, uygun bir şekilde olukların dâhil edilmesiyle elde edilen bir fonksiyon dikkate alınarak tekrar ifade edilmiştir. Olukların varlığı, hava aralığı ve mıknatıs bölgelerinde manyetik alanı değiştirir veya bozar; manyetik alan, oluklar arasındaki yarıçapın veya mesafenin bir fonksiyonu olarak değişir [29]. 


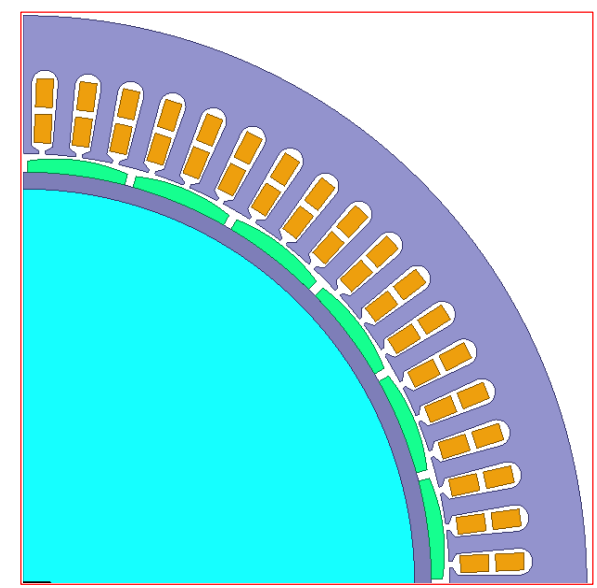

Şekil 1. Generatörün kesiti.

Tablo 1. KMSG'ye ait başlangıç özellikleri

\begin{tabular}{|c|c|}
\hline \multicolumn{2}{|c|}{ KMSG'ye ait teknik veriler } \\
\hline Çıkış gücü $(\mathrm{kW})$ & 4 \\
\hline $\operatorname{Anma~hızı~(d/d)~}$ & 250 \\
\hline Frekans $(\mathrm{Hz})$ & 50 \\
\hline Kutup sayısı (2p) & 24 \\
\hline Faz say1s1 & 3 \\
\hline Hat gerilimi (V) & 400 \\
\hline Hava aralığı uzunluğu (mm) & 1 \\
\hline $\begin{array}{l}\text { Bağ1l geçirgenlik } \\
\text { (Stator nüvesi-M19 (M310-50A)) }\end{array}$ & 970 \\
\hline Miknatıs (NdFeB-N40SH) kalınlığı (mm) & 5 \\
\hline Artık mıknatıslı akı yoğunluğu $B_{r}(\mathrm{~T})$ & 1.28 \\
\hline Bağıl geçirgenlik $\mu_{r e c}$ & 1.05 \\
\hline M1knatıslığg giderici kuvvet $H_{c}(\mathrm{kA} / \mathrm{m})$ & 989 \\
\hline Sicaklık (mak. ${ }^{\circ} \mathrm{C}$ ) & 150 \\
\hline
\end{tabular}

Çalışmanın kolaylığı için bazı varsayımlar dikkate alınmıştır:

- Kalıcı mıknatısların radyal olarak mıknatıslanması.

- Stator olukları dikdörtgen veya trapezoidal olarak basitleştirilmiştir.

- Ferromanyetik malzeme doğrusal bir B-H eğrisine sahiptir.

- Doyum ihmal edilmiştir.

- Miknatıslar dikdörtgen şeklindedir.

- Miknatıslar arasındaki mesafe, mıknatıslarla aynı geçirgenliğe sahiptir.

- Miknatıslar tarafindan üretilen manyetik alan, pürüzsüz bir stator yüzeyi varsayılarak 2 boyutlu bir çözümden elde edilir, yani oluk etkisi ihmal edilir.

- Manyetik alan dağılımı, mıknatıslar tarafından üretilen manyetik alan ve bağıl geçirgenlikten saptanır.

- Hava aralığı geçirgenliği, bir mıknatısın bir stator dişine baktığı yerde akının mıknatıs ve hava aralığından düz bir çizgi şeklinde ve mıknatıs bir oluk açıklığına baktığı 
pozisyonda bir dişin köşesinden merkezlenmiş dairesel bir yoldan geçtiği varsayılan bir alan modeline göre hesaplanır (Şekil 2).

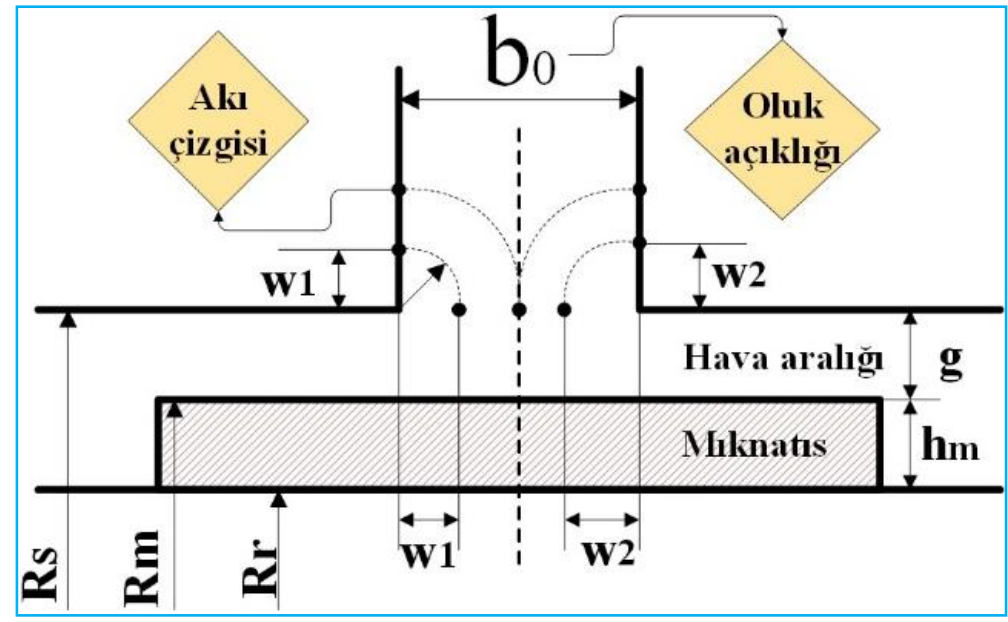

Şekil 2. Hava aralığındaki tahmini akı yolu.

\subsection{Mıknatıs Tarafından Üretilen Manyetik Alan ( Magnetic Field Produced by Magnet)}

Mıknatıslara bağlı manyetik alan, düz bir stator yüzeyi varsayarak, silindirik bir koordinat sisteminde modellenmiş iki boyutlu bir çözümden elde edilir [33]. İkinci çeyrek doğrusal mıknatıslanma karakteristiğine sahip mıknatıslarla donatılmış çok kutuplu bir makine için, mıknatıslanma vektörünün genliği (radyal olarak mıknatıslanma), Fourier serisi ile ifade edilebilir [33, 34];

$$
\begin{aligned}
& M=\frac{B_{r}}{\mu_{0}}=\sum_{n=1,3,5 \ldots}^{\infty} M_{r n} \cos (n p \theta) \\
& M_{r n}=2 \frac{B_{r}}{\mu_{0}} \alpha_{p} \frac{\sin \frac{n \alpha_{p} \pi}{2}}{\frac{n \alpha_{p} \pi}{2}}
\end{aligned}
$$

Burada $p$ kutup çifti sayısı, $\alpha_{p}=\tau_{m} / \tau_{p}$ mıknatıs yayı / kutup yayı oranı ve $\theta$ bir mıknatıs kutbunun merkezine referanslı açısal konumdur. Makinenin iç yarıçapında, yani. $r=R_{s}$ için, iç rotorlu makinelerde oluk etkisiz akı yoğunluğunun radyal bileşeninin genel ifadesi polar koordinat sisteminde hava aralığı manyetik potansiyel dağılım denklemlerinin çözümünden elde edilir [9, 29, 33, 34]. 


$$
\begin{aligned}
B_{g}(\theta)= & \frac{2 B_{r}}{\mu_{r}} \cdot \frac{\sin \left(\frac{\pi \alpha_{p}}{2}\right)}{n \pi} \cdot\left[\frac{\left.\left(\frac{R_{m}}{R_{s}}\right)^{2}-\left(\frac{R_{r}}{R_{s}}\right)^{2}+\left(\frac{R_{r}}{R_{s}}\right)^{2} \cdot \ln \left(\frac{R_{m}}{R_{r}}\right)^{2}\right]}{\left.\frac{\mu_{r}+1}{\mu_{r}}\left[1-\left(\frac{R_{r}}{R_{s}}\right)^{2}\right]-\frac{\mu_{r}-1}{\mu_{r}}\left[\left(\frac{R_{m}}{R_{s}}\right)^{2}-\left(\frac{R_{r}}{R_{m}}\right)^{2}\right]\right]}\right. \\
& \cdot\left[1+\left(\frac{R_{s}}{r}\right)^{2}\right] \cdot \cos (\theta)
\end{aligned}
$$

Eşitlik 2.3 'de, $R_{s}$ stator yüzeyindeki yarıçap1, $R_{m}$ mıknatıs yüzeyindeki yarıçapı, $R_{r}$ rotor gövdesinin yarıçapını ve $r=\left(\left(R_{s}+R_{m}\right) / 2\right)$ 'yi ifade eder. Oluk etkisi dikkate alındığında; stator oluk etkisi altındaki hava aralığı akı yoğunluğu aşağıdaki gibi hesaplanabilir [29].

$$
B_{g s}(\theta)=B_{g}(\theta) \cdot f_{P}(\theta)
$$

Burada $f_{P}(\theta)$, oluk etkisini hesaba katan hava aralığı bağıl geçirgenlik fonksiyonudur ve oluklardaki manyetik akı çizgilerinin Şekil 2'de gösterildiği gibi diş kenarlarına olan en kısa mesafeye eşit yarıçaplı yarı dairesel yollara sahip olduğu varsayımına dayanmaktadır [9].

\subsection{Bağıl Geçirgenlik Modeli (Relative Permeance Model)}

Stator oluklarının etkisini düzenleyen temel ilke, olukların üzerindeki manyetik alanın stator ferromanyetik malzemesine erişmek için daha ileri gitmesi gerçeğidir. Düzeltme faktörü olarak da bilinen bağıl geçirgenlik fonksiyonu, stator oluklarının etkisine uyacak şekilde stator yüzeyinde ideal manyetik alan dağılımına uygulanabilecek bir düzeltme faktörünü tanımlar [29].

Oluk etkisinde hava aralığı uzunluğu konuma göre değişir. Manyetik devre modeli ile oluk etkisiz olarak elde edilen hava aralığı akı yoğunluğu ve geçirgenlik katsayısının $(\operatorname{Pc}(\theta)=\mathrm{hm} /(\mathrm{g}(\theta) \mathrm{C} \phi))$ konuma göre değiştiği şekli ile sırasıyla aşağıdaki gibi yazılabilir [29, 35].

$$
\begin{gathered}
B_{g}=\frac{K_{l} C_{\phi}}{1+K_{r} \frac{\mu_{r e c}}{P_{c}}} B_{r} \\
B_{g s}=\frac{K_{l} C_{\phi}}{1+K_{r} \frac{\mu_{r e c}}{P_{c}(\theta)}} B_{r}
\end{gathered}
$$

Rotor, stator oluklarından geçerken, bağıl geçirgenlik veya oluk düzeltme faktörü, stator oluklarının bulunduğu bölgede hava aralığı ak1 yoğunluğunu değiştirir. Eşitlikler 2.4-2.6 kullanılarak düzeltme faktörü aşağıdaki gibi elde edilebilir [29]. 


$$
f_{P}(\theta)=\frac{B_{g s}}{B_{g}}=\left(\frac{K_{l} C_{\phi}}{1+K_{r} \frac{\mu_{r e c}}{P_{c}(\theta)}} B_{r}\right) /\left(\frac{K_{l} C_{\phi}}{1+K_{r} \frac{\mu_{r e c}}{P_{c}}} B_{r}\right)
$$

Düzeltme faktörü aşağıdaki gibi sadeleştirilebilir [29].

$$
f_{P}(\theta)=\frac{1+\frac{P_{c}}{K_{r} \mu_{r}}}{\frac{g(\theta)}{g}+\frac{P_{c}}{K_{r} \mu_{r}}}
$$

Eşitlik 2.7'den açıkça anlaşılabileceği gibi geçirgenlik katsayısının arttırılması oluk etkisini azaltır. Bu oluk düzeltme faktörünün ifadesini tamamlamak için, hava aralığı uzunluğundaki $\mathrm{g}(\theta)$ değişimin oluk alanı için belirtilmesi gerekir. En temel çözüm, $g(\theta)$ 'nın oluklar üzerinde son derece büyük olduğunu varsaymaktır. Fakat bu, oluklar üzerindeki hava aralığı akı yoğunluğunu sıfıra eşit hale getirir. Daha iyi bir çözüm ise Şekil 2'de tasvir edildiği gibi dairesel yay ve düz çizgi akı akış yaklaşımının kullanılmasıdır [29]. Bu durumda, $\mathrm{g}(\theta)=\mathrm{g}+(\pi / 2) \mathrm{w} 1$ burada w1 bir diş kenarından oluk alanı arasındaki doğrusal uzaklıktır.

Bu yaklaşım, Şekil 3'de gösterilen geometriye uygulanarak Eşitlik 2.8'deki hava aralığı uzunluğu g( $\theta)$ bir oluk adımı $(\theta \mathrm{s})$ için oluk etkili hale getirilmiştir.

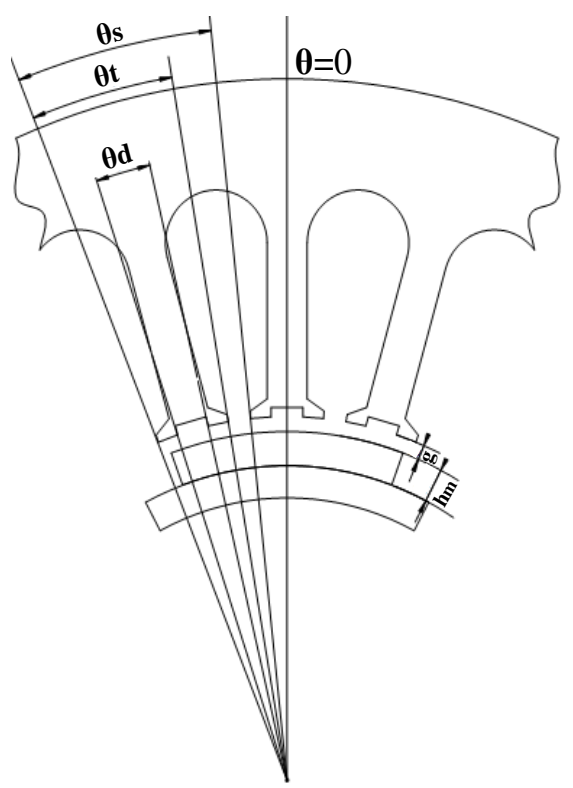

Şekil 3. Yeni generatör kesiti. 


$$
g(\theta)=\left\{\begin{aligned}
g+\frac{\pi}{2} \cdot R_{s} \cdot\left(\theta+\theta_{d} / 2\right) & \rightarrow \theta>-\theta_{d} / 2 \\
g+\frac{\pi}{2} \cdot R_{s} \cdot\left(\theta_{d} / 2-\theta\right) & \rightarrow \theta<\theta_{s} / 2 \\
g & \rightarrow \theta_{s} / 2 \leq|\theta| \leq \theta_{t} / 2 \\
g+\frac{\pi}{2} \cdot R_{s} \cdot\left(\theta-\theta_{t} / 2\right) & \rightarrow \theta_{t} / 2 \leq \theta \leq \theta_{s} / 2 \\
g-\frac{\pi}{2} \cdot R_{s} \cdot\left(\theta+\theta_{t} / 2\right) & \rightarrow-\theta_{s} / 2 \leq \theta \leq-\theta_{t} / 2
\end{aligned}\right\}
$$

Tüm açılar mekanik ölçüdedir. Manyetik alan elektriksel ölçüm açısından belirtildiğinden, Eşitlik 2.9 elektriksel ve mekanik ölçüm arasındaki ilişki $(\theta=\theta \mathrm{e} / \mathrm{p})$ kullanılarak yeniden yazılabilir [29]. Bir sonraki bölümde üzerinde durulacak olan tutma torkunun azaltılmasına yönelik gerçekleştirilecek stator modeli (Şekil 3) ve bu modele ait hava aralığı uzunluğu Eşitlik 2.9'da verilmiştir. Bu düzeltme modeli, manyetik alanın, dişin tüm yüzeyinde değişmediğini varsayar. Gerçekte, manyetik alan oluk alanına yaklaşırken biraz bozulmaya gerçekleşir [29].

\subsection{Tutma Torku (Cogging Torque)}

Tutma torkunu hesaplamak için kullanılan analitik metot genellikle stator oluklarındaki manyetik akı ve stator dişindeki doyumu ihmal eder. Tutma torku hesaplamaları, belirli bir tutma torku etkisini azaltma yöntemine bağlıdır. Tutma torku, rotor pozisyonuna bağlı olarak hava aralığında depolanan enerjinin değişim oranından veya hava aralığındaki manyetik akı yoğunluğundan elde edilir [36]. Literatürde genellikle generatörün analitik modeli oluksuz ya da dikdörtgen oluk yapısı varsayımına dayandırılarak oluşturulmuştur. Bu çalışmada ise bir önceki bölümde açıklanan bağıl geçirgenlik fonksiyonu kullanılarak elde edilen hava aralığı akı yoğunluğunun etkileşimi kullanılarak elde edilmiştir.

Tutma torku, oluk açıklığı nedeniyle sabit olmayan hava aralığı relüktansından kaynaklanan torktur (diğer bir deyişle, rotorun düşük manyetik alan yollarıyla hizalanma eğiliminden dolayı) [9]. Eşitlik 2.10'da verilen tutma torku, Şekil 2'de gösterildiği gibi, diş duvarlarına giren akılar tarafından üretilir. Alternatif olarak, tutma torku boş stator akımları ile açısal pozisyonda manyetik enerjinin değişim oranı olarak hesaplanabilir.

$$
T_{c o g}(\theta)=\frac{L}{2 \mu} \sum_{m=1}^{Q}\left[\left(\int_{0}^{b_{s 0} / 2} B_{g s m}^{2}(w 1) \cdot\left(R_{s}+w 1\right) \cdot d w 1\right)-\left(\int_{b_{s 0} / 2}^{b_{s 0}} B_{g s m}^{2}(w 2) \cdot\left(R_{s}+w 2\right) \cdot d w 2\right)\right]
$$

Tutma torku, bir Fourier serisi açılımı kullanılarak aşağıdaki gibi tanımlanabilir:

$$
T_{c o g}(\theta)=\sum_{k=1}^{\infty} T_{k} \sin \left(k Q \theta_{m}+\theta\right)
$$

Burada $\theta_{m}$ olukların açısal pozisyonu, $\theta$ ise rotordaki açısal yer değiştirmedir. $T_{k}$ katsayısı Eşitlik 2.10'dan sayısal olarak aşağıdaki gibi ifade edilebilir.

$$
T_{k}(\theta)=\frac{\pi \cdot L \cdot R_{s}}{2 \cdot \mu_{0} \cdot Q} \sum_{m=1}^{Q}\left[B_{g s m}^{2}\left(\frac{2 \pi}{Q} m+\theta\right) \cdot\left(R_{s}+g_{\theta}\right) \cdot s p\right]
$$


Burada,

- $s p=l$ ve $g_{\theta}=w l+g$; pozisyon oluk açıklığının sol tarafında.

- $s p=-1$ ve $g_{\theta}=w 2+g$; pozisyon oluk açıklığının sağ tarafında.

- $s p=0$ ve $g_{\theta}=0$; oluk açıklığ dışındaki pozisyonlarda.

\subsection{Zit Emk (Back Emf)}

Zıt emk, hava aralığında değişken manyetik alan tarafından stator sargılarında indüklenen gerilimdir. Zıt emk'nın elde edilmesi ile ilgili iki genel tanımlama vardır. Bunlardan birincisi, zit emk'y1 sadece rotor manyetik alanın etkisi olarak görür. Diğeri ise, zıt emk'nın bir parçası olarak sargılar arasındaki karşılıklı ve öz indüklemeden oluşan gerilimi içerir [9]. Bilindiği gibi bir devrede (birincil) üretilen değişen manyetik alan, bir ikinci devrede (ikincil) değişen gerilim ve akım indükleyebilir. İki devrenin ortak endüktansı $M$, birincil devredeki akım değişikliklerden kaynaklanan ikincil devredeki gerilimin boyutunu tanımlar. Bu çalışmada, ikinci tanım kullanılmıştır.

Bir fazın zıt emk değeri, o fazın her bobini tarafından indüklenen gerilimlerin toplamı olarak ifade edilebilir $[9,37]$.

$$
E_{A}(t)=-\sum_{j=1}^{Q_{s}} \frac{d \Phi_{j}}{d t}=-\sum_{j=1}^{Q_{s}} \frac{d \int_{0}^{b_{s 0}} L \cdot B_{j}(t) d w 1}{d t}
$$

Burada $\phi_{j}$ herhangi bir oluktaki manyetik akıdır. Eşitlik 4.17'nin sayısal ifadesi aşağıdaki gibidir.

$$
\begin{aligned}
E_{A}(t) & =\frac{L \cdot R_{s} \cdot \omega}{Q_{s}} \sum_{m=1}^{Q_{s}} \times\left[B_{g s_{n}}(\theta+\omega t)+B_{A_{n}}(\theta)+B_{B_{n}}(\theta)+B_{C_{n}}(\theta)\right] \\
& \times \operatorname{sp}(\theta)
\end{aligned}
$$

Burada $Q_{s}$, stator oluk sayısıdır. Ayrica;

- $s p(\theta)=1 ; \theta_{1}$ A fazının oluğunda ve iletkenin akım yönü pozitifse.

- $s p(\theta)=-1 ; \theta_{1}$ A fazının oluğunda ve iletkenin akım yönü negatifse.

- $s p(\theta)=0$; diğer koşullarda.

\subsection{Eşdeğer Devre Modeli (Equivalent Circuit Model)}

Elektrik makinalarının karmaşık yapısında, her an değişebilen çalışma koşullarına göre hesap yapmak, endüvi sargılarından akan akımları, momenti, gücü, güç faktörünü, kayıpları ve diğer çıkış parametrelerini hesaplamak oldukça zaman alıcı ve hata yapmaya müsait karmaşık bir işlemdir. Bu zorluğu önlemek ve karmaşıklığ 1 gidermek için KMSG'nin bir faz modeli Şekil 4'te gösterildiği gibi çıkartılmıştır. 


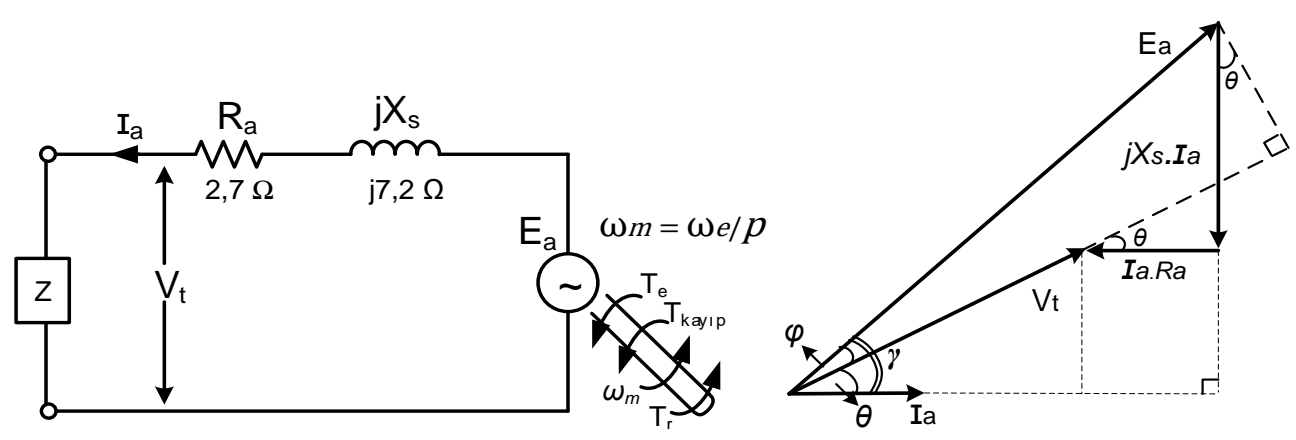

Şekil 4. KMSG’nin bir faz eşdeğer devresi ve fazör diyagramı.

Şekil 4'te; $R_{a}$ ve $X_{s}$ sırasıyla, sargı direnci ve senkron reaktansı temsil eder, $\theta$ güç katsayı açısı, $\varphi$ güç açısı veya moment açısı, $\gamma$ ise indüklenen gerilim $E_{a}$ ve $I_{a}$ arasındaki açıdır. $\Phi$ manyetik akı, $N$ faz başına seri sarım sayısı, $\omega_{e}$ elektriksel hızdır. Diğer taraftan, faz gerilimi ve akımın, fazör gösterimiyle $(\sim)$ ifadesi sırasıyla, Eşitlik 2.15 ve 2.16’te verilmiştir.

$$
\begin{gathered}
\tilde{V}_{t}=\sqrt{\tilde{E_{a}^{2}-\left(X_{s} \tilde{I_{a}} \cos \theta-R_{a} \tilde{I_{a}} \sin \theta\right)^{2}}}-R_{a} \tilde{I_{a}} \cos \theta-X_{s} \tilde{I_{a}} \sin \theta \\
\tilde{I_{a}}=\tilde{E_{a}} /\left(R_{a}+j X_{S}+Z\right)
\end{gathered}
$$

\section{TUTMA TORKUNUN AZALTILMASI (MINIMIZATION OF COGGING TORQUE)}

Tutma torkunun azaltılması ile ilgili olarak literatürde birçok yöntem önerilmiştir. Kutup başına kesirli oluk sayısı, stator yığınında veya mıknatıs kutuplarında çarpıklık işlemi [4-6], kutup yayı/kutup adımı oranı değişimi (0-1), eksenel bölütleme veya mıknatıs kaydırma bu yöntemlerden bazılarıdır [1-3, 7, 8]. Ayrıca oluk açıklığı, mıknatıs kalınlığı ve hava aralığı genişliği gibi parametrelerin diğer çıkış değerleri de göz önünde bulundurularak optimum değerlerinin bulunması, tutma torkunu azaltmak için diğer bir yaklaşımdır [8].

Stator yığınında çarpıklık işlemi her ne kadar çok tercih edilse de nihai ürünün imalatını karmaşıklaştırmasından dolayı ilave maliyetlere neden olmaktadır. $\mathrm{Bu}$ yöntem sarg1 yerleşimini zorlaştırabilir, etkin oluk alanını azaltır, iletken uzunluğu artar ve dolayısıyla stator direnci de artar [3]. $\mathrm{Bu}$ çalışmada, bahsedilen yöntemlerin dışında tutma torkunu azaltmak için statorda yardımcı dişler [27] açılarak geliştirilen yeni stator yapısının tutma torkuna ve indüklenen gerilime etkisi ortaya konmuştur.

\subsection{Düşük Tutma Torku İçin Stator Tasarımı (Stator Design for Low Cogging Torque)}

$\mathrm{Bu}$ çalışmada önerilen yeni lamine yapısı ile stator dişleri kenarlarında manyetik doygunluğu azaltarak daha düşük tutma torku sağlamak ve böylelikle daha yüksek tork yoğunluğunun elde edilmesi amaçlanmaktadır. Tutma torkunu azaltmak için geliştirilen 5-farklı geometrideki stator diş yapısının makine performansı üzerine etkilerini analiz etmek için Maxwell 2D Design yazılımının manyetik geçici çözüm tipi kullanılmıştır. Geçici (Transient) çözücü ile 0-0,02 s arasında 0,0006 s'lik zaman adımı (time stepping) ile manyetik alan ve hareket denklemi hesaplanmaktadır. SEA ile elde edilen sonuçlar optimum tutma torkunun hangi lamine yapısında gerçekleştiğini ortaya koymuştur. Ayrıca kullanılan analitik modele ait sonuçlar SEA ile karşılaştırmalı olarak verilmiştir.

Tutma torku, rotorun açısal pozisyonuna bağlı olarak hava aralığında depolanan enerjinin değişim oranı veya yanal kuvvetlerin toplamıyla manyetik akı yoğunluğu değişiminden elde edilir [1]. Tork hesabı için en kritik alanlar hava aralığı ve hemen yakınıdır. Böylece, bant ağı doğru sonuçlar için çok önemlidir. 
Oluşturulan ağ simülasyon hızı ve doğruluğu açısından çok kritik bir konudur. Burada sadece tatmin edici sonuçlar verecek kaba bir ağ uygulanmıştır.

Eşitlik 12'den anlaşılabileceği gibi tutma torku hava aralığı akı yoğunluğunun karesi ile doğru orantılıdır. Bu yüzden hava aralığı akı yoğunluğunu azaltmak için oluk açıklığı, oluk açıklığı yüksekliği ve kama yüksekliği gibi oluk parametrelerine (hs0, hs1, hs2 ve bs0-Tablo 2) bağli olarak Tablo 3 'de belirtilen boyutlarda statorda çentikler açılmıştır;

Tablo 2. Önerilen model için kullanılan oluk parametreleri

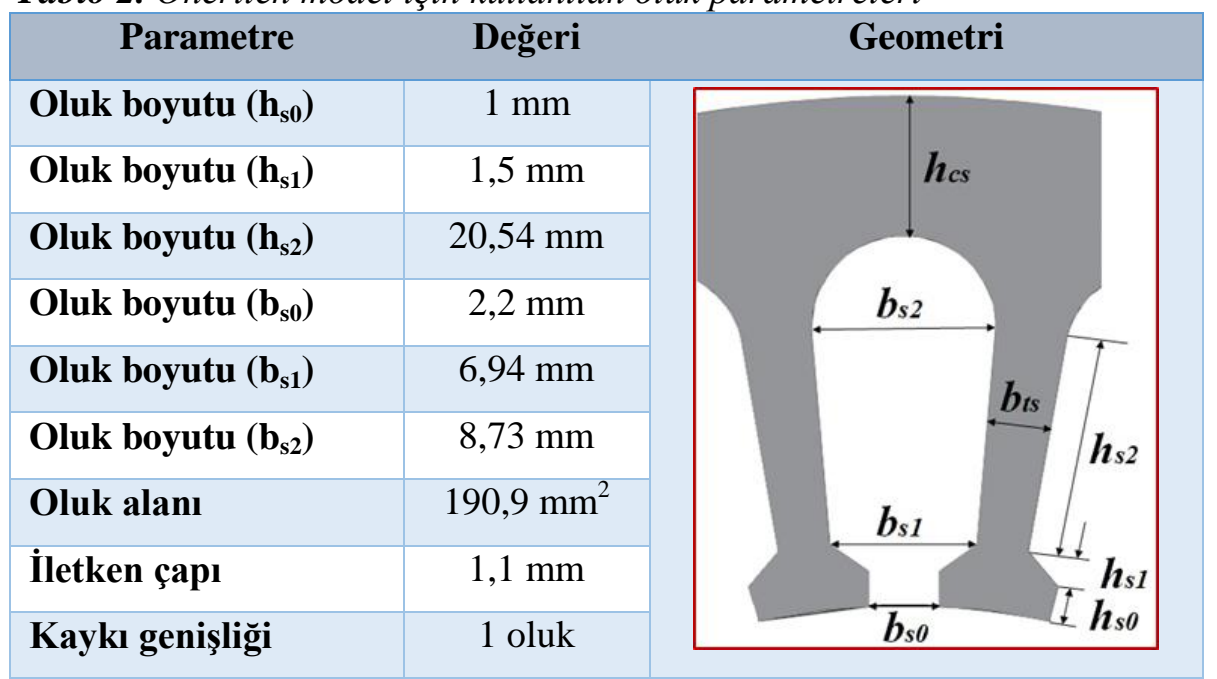

Tablo 3. Önerilen stator yapıları ve parametreleri

\begin{tabular}{|l|c|c|}
\hline Yapı & Çentik Genişliği & Çentik Yüksekliği \\
\hline Model_1 & bs0 $(2.2 \mathrm{~mm})$ & hs0 $(1 \mathrm{~mm})$ \\
\hline Model_2 & 2xbs0 $(4.4 \mathrm{~mm})$ & hs0 $(1 \mathrm{~mm})$ \\
\hline Model_3 & bs0 $(2.2 \mathrm{~mm})$ & hs0 + hs $1(2.5 \mathrm{~mm})$ \\
\hline Model_4 & Çift bs0 $(2.2 \mathrm{~mm})$ & Çift hs0 $(1 \mathrm{~mm})$ \\
\hline Model_5 & yok & yok \\
\hline
\end{tabular}

Açılan yardımcı dişler ile SEA için oluşturulan generatör yapıları Şekil 5'de verilmiştir. Tutma torkunun analizi için rotor $1 \mathrm{~d} / \mathrm{s}^{\prime}$ lik sabit bir hızda, bir oluk adımını (5) kapsayacak şekilde ve açılan çentiği hesaba katarak $0^{\circ}-7,5^{\circ}$ arasında (360/10000)x6=0,216 mekanik derece ile döndürülmüştür.

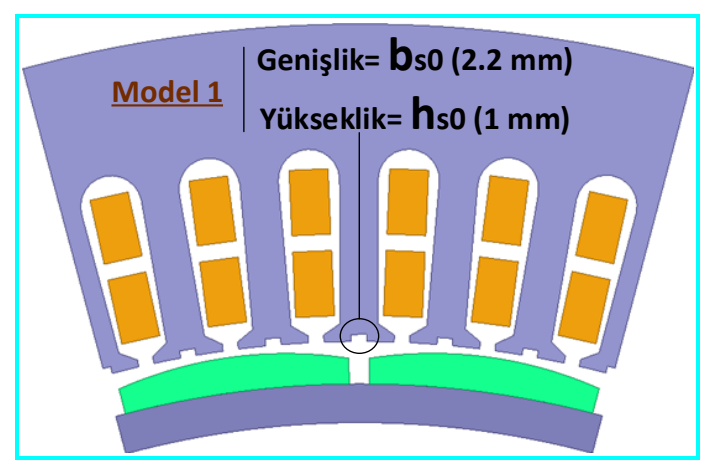

(a)

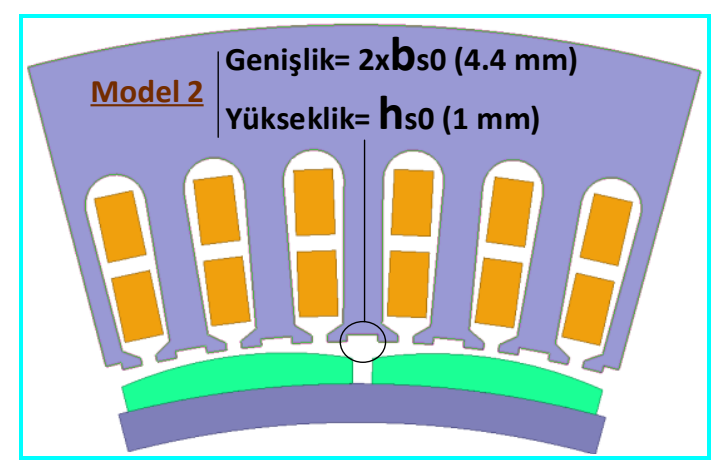

(b) 


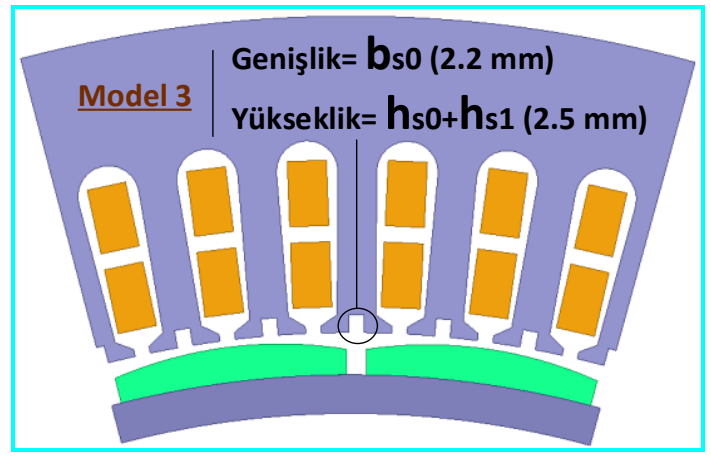

(c)

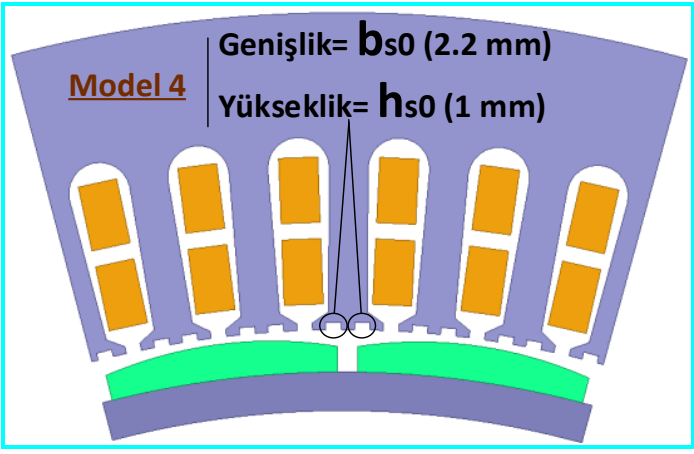

(d)

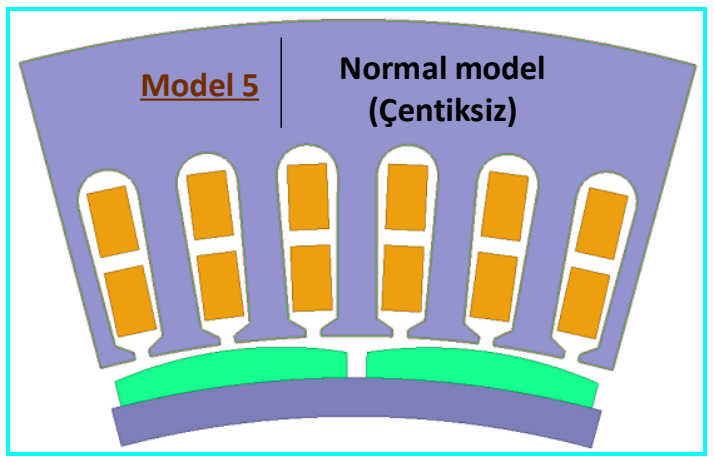

(e)

Şekil 5. Tutma torku analizi için stator dişlerinde açılan çentik modelleri, a) oluk açılklı̆̆ ve oluk açıklı̆̆l yüksekliğinde, b) 2xoluk açıklı̆̆l ve oluk açıkll̆̆g yüksekliğinde, d) çift çentikli, e)normal model (çentiksiz).

Şekil 6 oluk parametrelerine bağlı olarak geliştirilen yeni stator modeli ve oluk etkili normal stator modeline ait tutma torku eğrilerini karşılaştırmalı olarak vermektedir. En düşük tutma torku değerinin Model_4'deki diş açıklığında elde edildiği ortaya konmuştur. Grafikler incelendiğinde açılan diş bölgelerinde tutma torkundaki azalmalar gözlemlenmiştir.

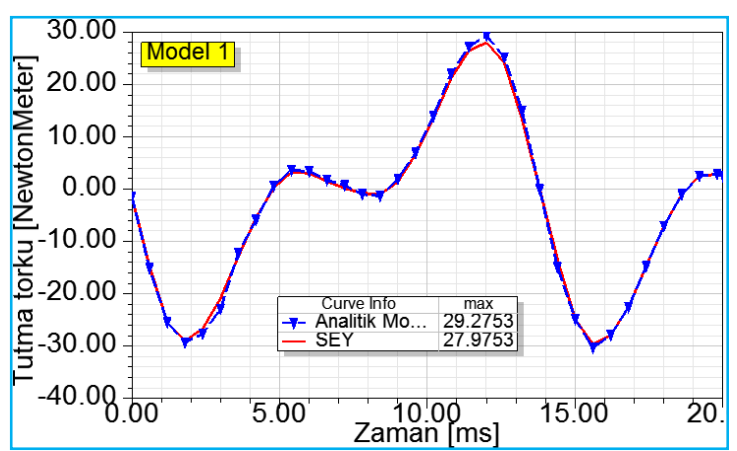

(a)

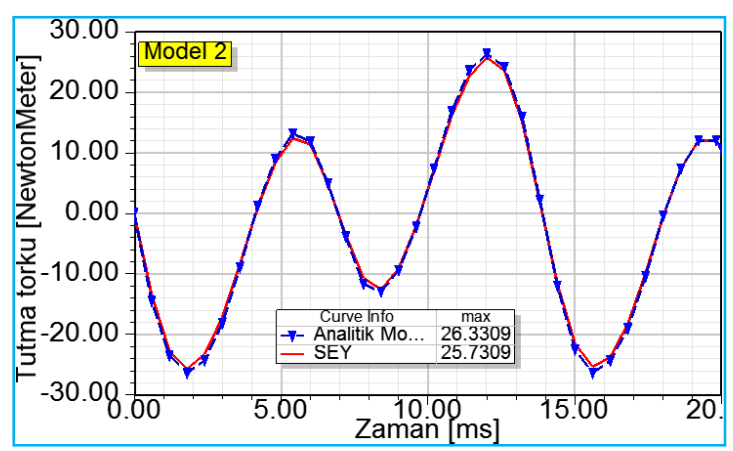

(b) 


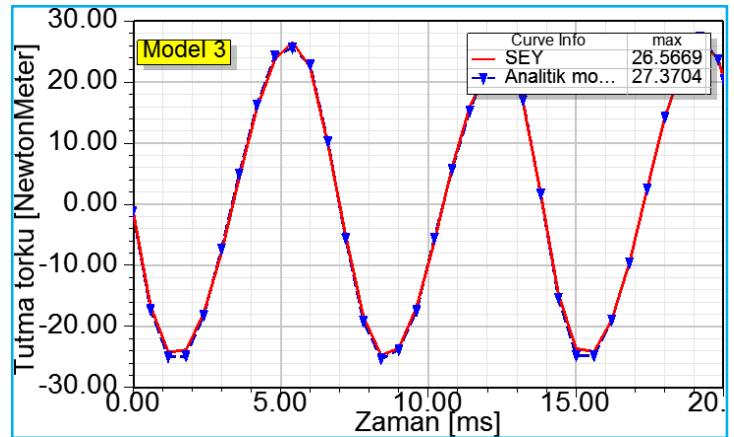

(c)

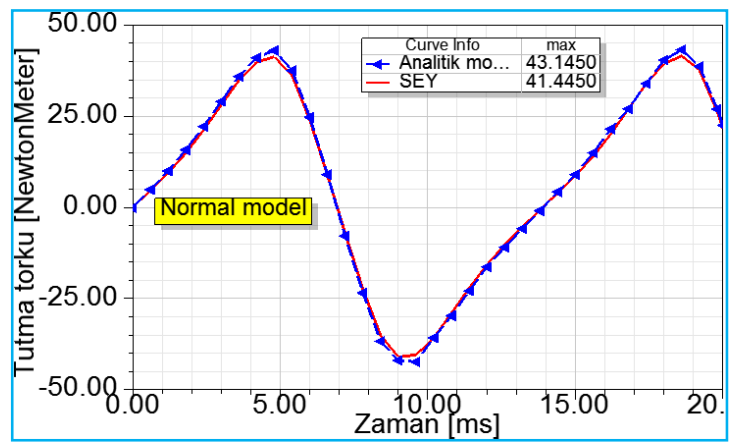

(e)

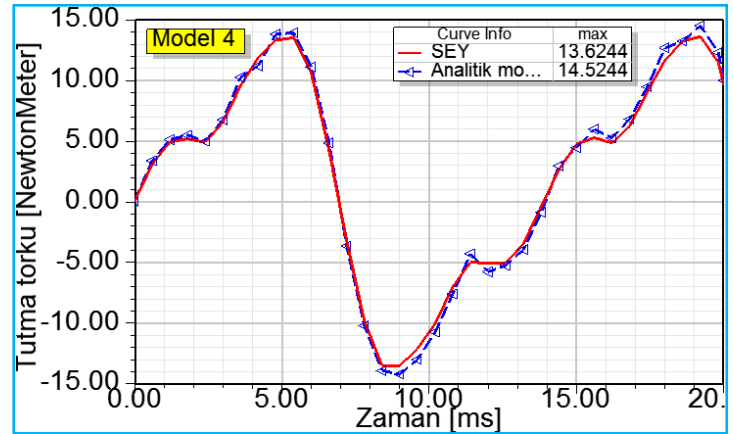

(d)

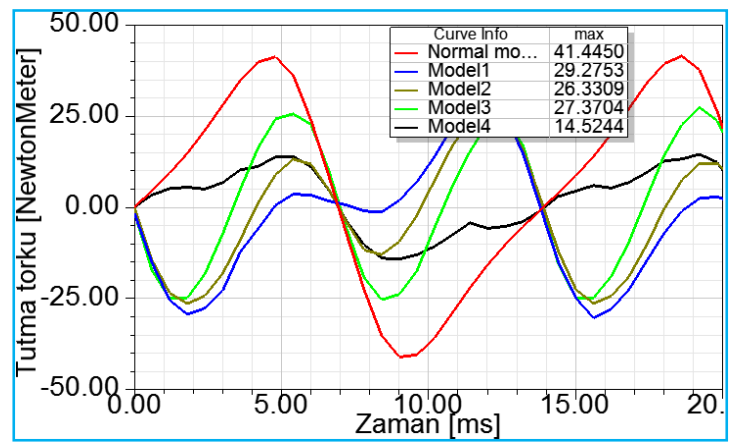

(f)

Şekil 6. Önerilen stator yapısı için tutma torku sonuçları, a) model1, b) model2, c) mode13, d) mode14, e) model 5, f) tüm modeller

Ayrıca, 5 model için elde edilen tutma torku, faz gerilimleri, faz akımları ve demir kayıplarına ait değerler Tablo 4'te verilmiştir. Tablo 4 incelendiğinde tutma torkundaki iyişme ile birlikte makinenin performansı faz gerilimi, faz akımı ve çıkış gücü açısından beklentileri karşılayacak nitelikte kalmıştır. Karşılaştırmalı olarak verilen SEA ve analitik sonuçlar bu çalışmada önerilen analitik modeli doğrular niteliktedir. Bu parametrelere ilave olarak bu modellerin gerilim ve akımın harmonik bileşenlerine etkileri de incelenebilir.

Tablo 4. Bazı parametrelere bağlı olarak elde edilen karşılaştırma sonuçları

\begin{tabular}{|l|c|c|c|c|c|}
\hline \multicolumn{1}{|c|}{ Generatör } & $\begin{array}{c}\text { Tutma Torku } \\
(\mathbf{N m})\end{array}$ & $\begin{array}{c}\text { Faz Gerilimi } \\
(\mathbf{V})\end{array}$ & $\begin{array}{c}\text { Faz Akımı } \\
(\mathbf{A})\end{array}$ & $\begin{array}{c}\text { Çıkış } \\
\text { Gücü (kW) }\end{array}$ & $\begin{array}{c}\text { Demir Kaybı } \\
(\mathbf{W})\end{array}$ \\
\hline $\begin{array}{l}\text { Model_1 } \\
\left(h_{s 0^{-}} b_{s 0}\right)\end{array}$ & 27,9 & 264 & 7,2 & 4,7 & 24,6 \\
\hline $\begin{array}{l}\text { Model_2 } \\
\left(h_{s 0^{-}} 2 . b_{s 0}\right)\end{array}$ & 25,7 & 259 & 7,1 & 4,49 & 23,6 \\
\hline $\begin{array}{l}\text { Model_3 } \\
\left(\left(h_{s 0}+h_{s 1}\right)-b_{s 0}\right)\end{array}$ & 27,3 & 255 & 6,9 & 4,32 & 23,1 \\
\hline $\begin{array}{l}\text { Model_4 } \\
2 \text { tane }\left(h_{s 0^{-}} b_{s 0}\right)\end{array}$ & 14,5 & 262 & 7,1 & 4,67 & 24,3 \\
\hline $\begin{array}{l}\text { Model_5 } \\
\text { Normal model }\end{array}$ & 41,4 & 269 & 7,36 & 4,87 & 25,3 \\
\hline
\end{tabular}


Şekil 7, generatör tam yükte ve yüksüz durumda iken SEA ve önerilen analitik model ile elde edilen faz gerilimlerini karşılaştırmalı olarak sunmaktadır. Önerilen analitik model SEA sonuçları ile iyi bir eşleşme göstermektedir.

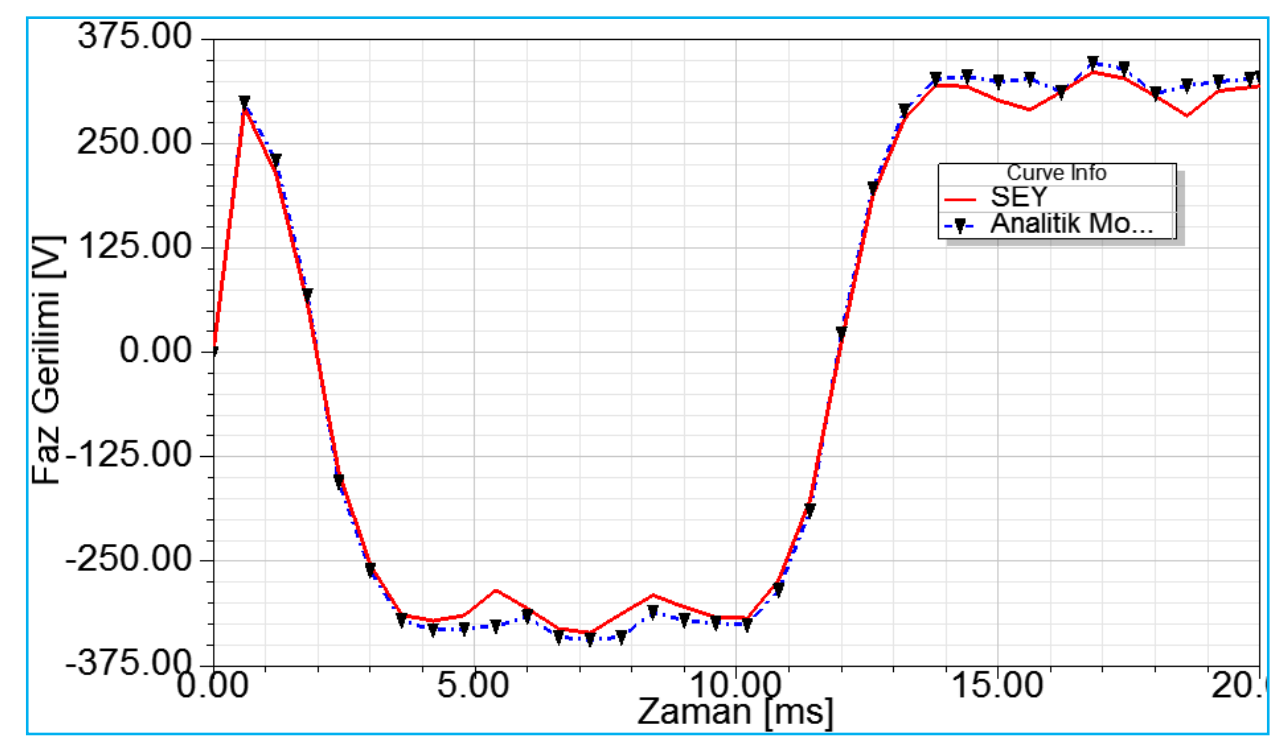

(a)

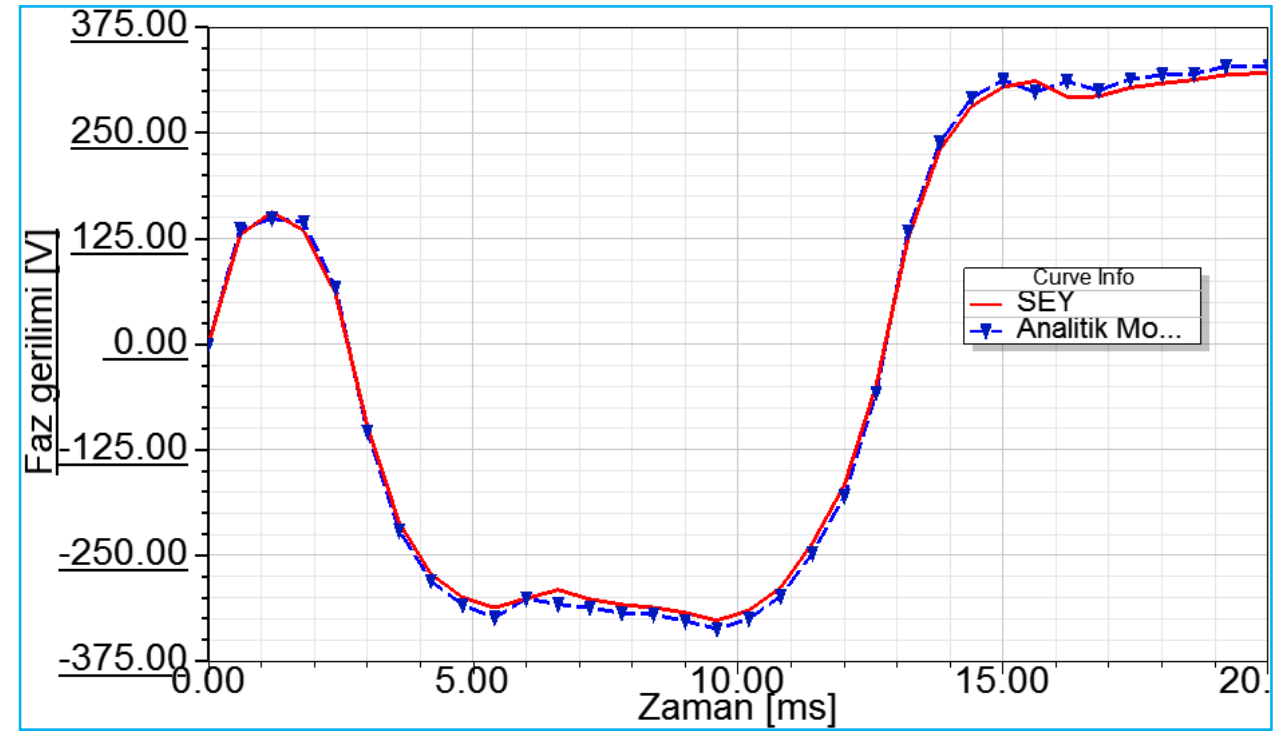

(b)

Şekil 7. Faz gerilimleri, a) yüksüz, b) tam yükte.

\section{SONUÇ (CONCLUSION)}

$\mathrm{Bu}$ çalışmada, kalıcı mıknatıslı generatörlerde tutma torkunu azaltmak için yeni lamine yapısı önerilmiştir. Önerilen yapıda stator dişlerinde oluk açıklığ $(\mathrm{bs} 0=2.2 \mathrm{~mm})$, oluk açıklığ 1 yüksekliği $(\mathrm{hs} 0=1 \mathrm{~mm})$ ve kama yüksekliği $(\mathrm{hs} 1=1.5 \mathrm{~mm})$ gibi oluk parametrelerine bağlı olarak çentikler açılmıştır. Yapısal değişikliği ve analitik yöntemi uygulamak için, 4-kW, 24-kutuplu ve 72 oluklu radyal akılı makine tasarlanmış ve optimize edilmiştir. Gerçekleştirilen yapısal tasarım ve sonucunda;

1. Stator dişleri kenarlarında manyetik doygunluğu azaltarak daha düşük tutma torku sağlanmıştır.

2. Minimum tutma torku değeri çift çentikli (genişlik=2.2 $\mathrm{mm}$ ve yükseklik=1 mm) modelde elde edilmiştir. 
3. Çift çentikli model normal model ile karşılaştırıldığında, tutma torkunda \% 64,9'luk bir azalma gerçekleşirken faz geriliminde \% 2,6 ve çıkış gücünde ise \% 4'lük azalma meydana gelmiştir.

4. Böylelikle daha yüksek tork yoğunluğu elde edilmiştir.

5. Farklı stator yapıları için en düşük tutma torku değeri 2 tane (hs0- bs0) diş yapısında gerçekleşmiştir.

6. Bunun yanında çıkış gücü ve çıkış gerilimi gibi parametrelerin istenen değerlerde olduğu tespit edilmiştir.

Yeni yapının analitik çözümü için bağıl geçirgenlik fonksiyonu kullanılmıştır. Ayrıca analitik çözüm sonuçları SEA ile karşılaştırılmıştır. Önerilen analitik yöntemde SEA'ya göre \% 4,5'lik bir sayısal hata gözlemlenmiştir. SEA'da oluşturulan ağ simülasyon hızı ve doğruluğu açısından çok kritik bir konudur. Burada sadece tatmin edici sonuçlar verecek kaba bir ăg uygulanmıştır. Bütün hareketli parçaları çevreleyen bant'ın yüzeyine ve iç kısmına da uzunluk bazlı bir ağ uygulandığında ve aynı zamanda eğri elemanlı bir ağ kullanıldığında SEA daha doğru ve kesin sonuçlar verebilir. Böylelikle önerilen analitik yöntemde SEA'ya göre sayısal hata yükselecektir.

\section{KAYNAKLAR (REFERENCES)}

[1] L. Dosiek, P. Pillay, Cogging torque reduction in permanent magnet machines. IEEE Transactions on industry applications, 43: 6 (2007) 1565-1571.

[2] D. Wang, X. Wang, S. Y. Jung, Cogging torque minimization and torque ripple suppression in surface-mounted permanent magnet synchronous machines using different magnet widths. IEEE Transactions on Magnetics, 49: 5 (2013) 2295-2298.

[3] E. Muljadi, J. Green, Cogging torque reduction in a permanent magnet wind turbine generatör. In ASME 2002 Wind Energy Symposium, American Society of Mechanical Engineers, USA, (2002) 340-342.

[4] S. J. Arand, M. Ardebili, Multi-objective design and prototyping of a low cogging torque axial-flux PM generator with segmented stator for small-scale direct-drive wind turbines. IET Electric Power Applications, 10: 9 (2016) 889-899.

[5] D. R. McIntosh, Skewing For Both Cogging Torque Components In Permanent Magnet Machines. Proceedings of the COMSOL Conference, Boston, (2010) 1-5.

[6] N. Bianchi, S. Bolognani, Design techniques for reducing the cogging torque in surface-mounted PM motors. IEEE Transactions on Industry Applications, 38: 5 (2002) 1259-1265.

[7] W. Fei, P. C. K. Luk, A new technique of cogging torque suppression in direct-drive permanentmagnet brushless machines. IEEE Transactions on Industry Applications, $46: 4$ (2010) 1332-1340.

[8] Z. Q. Zhu, D. Howe, Influence of design parameters on cogging torque in permanent magnet machines. IEEE Transactions on energy conversion, 15: 4 (2000) 407-412.

[9] A. B. Proca, A. Keyhani, A. El-Antably, W. Lu, M. Dai, Analytical model for permanent magnet motors with surface mounted magnets. IEEE transactions on energy conversion, 18: 3 (2003) 386-391.

[10] T. L. Tiang, D. Ishak, M. K. M. Jamil, Complete subdomain model for surface-mounted permanent magnet machines. In Energy Conversion (CENCON), (2014) 140-145.

[11] Y. Zhou, H. Li, G. Meng, S. Zhou, Q. Cao, Analytical Calculation of Magnetic Field and Cogging Torque in Surface-Mounted Permanent-Magnet Machines Accounting for Any Eccentric Rotor Shape. IEEE Transactions on Industrial Electronics, 62: 6 (2015) 3438-3447. 
[12] B. Ackermann, R. Sottek, Analytical modeling of the cogging torque in permanent magnet motors. Electrical Engineering (Archiv fur Elektrotechnik), 78: 2 (1995) 117-125.

[13] Z. Q. Zhu, L. J. Wu, Z. P. Xia, Z.P., “An accurate subdomain model for magnetic field computation in slotted surface-mounted permanent-magnet machines", IEEE Transactions on Magnetics, 46(4): 1100-1115 (2010).

[14] A. Bellara, Y. Amara, G. Barakat, B. Dakyo, Two-dimensional exact analytical solution of armature reaction field in slotted surface mounted PM radial flux synchronous machines. IEEE Transactions on Magnetics, 45: 10 (2009) 4534-4538.

[15] Z. Q. Zhu, D. Howe, E. Bolte, B. Ackermann, Instantaneous magnetic field distribution in brushless permanent magnet DC motors. I. Open-circuit field. IEEE transactions on magnetics, 29: 1 (1993) 124-135.

[16] Y. Zhou, H. Li, W. Wang, Q Cao, S. Zhou, Improved Method for Calculating Magnetic Field of Surface-Mounted Permanent Magnet Machines Accounting for Slots and Eccentric Magnet Pole. Journal of Electrical Engineering \& Technology, 10: 3 (2015) 1025-1034.

[17] Z. J. Liu, J. T. Li, Analytical solution of air-gap field in permanent-magnet motors taking into account the effect of pole transition over slots. IEEE Transactions on Magnetics, 43: 10 (2007) 38723883.

[18] H. K. Yeo, D. K. Woo, D. K. Lim, J. S. Ro, H. K. Jung, Analysis of a surface-mounted permanentmagnet machine with overhang structure by using a novel equivalent magnetic circuit model. Journal of Electrical Engineering \& Technology, 9: 6 (2014) 1960-1966.

[19] R. Qu, T. A. Lipo, Analysis and modeling of airgap \& zigzag leakage fluxes in a surface-mountedPM machine. In Industry Applications Conference, 37th IAS Annual Meeting, USA, (2002) 25072513.

[20] X. F. Ding, G. L. Liu, H. Guo, H. Bai, A 3-D Magnetic Equivalent Circuit of an Axial-Flux MEMS Micromotor. Applied Superconductivity and Electromagnetic Devices, China, (2016).

[21] Z. Q. Zhu, Y. Pang, D. Howe, S. Iwasaki, R. Deodhar, A. Pride, Analysis of electromagnetic performance of flux-switching permanent-magnet machines by nonlinear adaptive lumped parameter magnetic circuit model. IEEE Transactions on magnetics, 41: 11 (2005) 4277-4287.

[22] Z. Q. Zhu, D. Howe, Instantaneous magnetic field distribution in brushless permanent magnet DC motors. III. Effect of stator slotting. IEEE transactions on magnetics, 29: 1 (1993) 143-151.

[23] D. Zarko, D. Ban, T. A. Lipo, Analytical solution for cogging torque in surface permanent-magnet motors using conformal mapping”, IEEE Transactions on Magnetics, 44: 1 (2008) 52-65.

[24] D. Zarko, D. Ban, T. A. Lipo, Analytical calculation of magnetic field distribution in the slotted air gap of a surface permanent-magnet motor using complex relative air-gap permeance. IEEE Transactions on Magnetics, $42: 7$ (2006) 1828-1837.

[25] M. Markovic, M. Jufer, Y. Perriard, Reducing the cogging torque in brushless dc motors by using conformal mappings. IEEE transactions on magnetics, 40: 2 (2004) 451-455.

[26] R. Rabinovici, Magnetic field analysis of permanent magnet motors. IEEE transactions on magnetics, 32: 1 (1996) 265-269.

[27] A. Jabbari, Design optimization of a permanent magnet brushless generator for a gearless wind türbine. In Renewable Energy \& Distributed Generation (ICREDG), (2016) 56-62. 
[28] J. F. Gieras, Permenant Magnet Motor Technology Desing And Applications. CRC Press is an imprint of Taylor \& Francis Group, USA, (2010) 172-205.

[29] D. Hanselman, Brushless permanent magnet motor design. Magna Physics Publishing, Lebanon, (2006) 151-181.

[30] J. R. Hendershot, T. J. Miller, Design of brushless permanent-magnet motors. Magna Physics Publishing, New York, (1994) 94-200.

[31] J. G. Wanjiku, Design of an axial-flux generator for a small-scale wind electrolysis plant. Diss. University of Cape Town, (2010).

[32] C. Y. Hsiao, S. N. Yeh, J. C. Hwang, Design of high performance permanent-magnet synchronous wind generators. Energies, 7: 11 (2014) 7105-7124.

[33] Z. Q. Zhu, D. Howe, Analytical prediction of the cogging torque in radial-field permanent magnet brushless motors. IEEE transactions on magnetics, 28: 2 (1992) 1371-1374.

[34] Z.Q. Zhu, D. Howe, C.C. Chan, Improved analytical model for predicting the magnetic field distribution in brushless permanent-magnet machines. IEEE Transactions on Magnetics, 38: 1 (2002) 229-238.

[35] Y. Cetinceviz, D. Uygun, H. Demirel, Optimal Design and Verification of a PM Synchronous Generator For Wind Turbines. International Journal of Renewable Energy Research (IJRER), 7: 3 (2017) 1324-1332.

[36] J. F. Gieras, Analytical approach to cogging torque calculation of PM brushless motors. IEEE Transactions on Industry Applications, 40: 5 (2004) 1310-1316.

[37] E. Yıldırız, M. T. Aydemir, Küçük Güçlü Bir Rüzgâr Jeneratöründe Kullanım İçin Eksenel Akılı Bir Sürekli Mıknatıslı Motorun Analizi, Tasarımı ve Gerçekleştirilmesi. Gazi Üniversitesi MühendislikMimarlık Fakültesi Dergisi 24: 3 (2009) 525-531. 